\title{
Fertility preservation
}

\author{
Bettina Böttcher (D) J Julian Marschalek
}

Received: 13 September 2020 / Accepted: 16 September 2020

(C) Springer-Verlag GmbH Austria, part of Springer Nature 2020

Research into fertility preservation (FP) techniques has increasingly gained in importance over the last few years, as improved oncologic screening methods and therapies progressively result in cancer being diagnosed at a younger age, thus, ensuring better survival rates following oncologic therapy.

It is well known, however, that chemo- and radiotherapy bear the risk of irreversible impairment of a woman's fertility to the extent of premature ovarian insufficiency (POI). Furthermore, more and more non-oncologic conditions are steadily securing access to FP techniques. This is a consequence of an increased awareness regarding this upcoming field. Besides endometriosis, autoimmune or hematologic diseases, Turner syndrome, transsexualism and a family history of POI, social or occupational reasons motivate women to protect their chances of parenthood by means of social or medical egg freezing.

Appropriate counseling of women who wish to preserve their fertility is complex, and oftentimes a multidisciplinary challenge for reproductive gynecologists, oncologists, radiotherapists, psychologists and other medical professional. Unfortunately, only a small number of patients are referred to FP counseling. The most probable causes of this lack of counselling is a lack of time, especially if oncologic treatment needs to be started urgently. However, there is also

PD. Dr. med. B. Böttcher, MA $(\varangle)$

Department of Gynecological Endocrinology and Reproductive Medicine, Medical University of Innsbruck, Anichstraße 35, 6020 Innsbruck, Austria bettina.boettcher@i-med.ac.at

Dr. J. Marschalek, MD

Department of Gynecological Endocrinology and Reproductive Medicine, Medical University of Vienna General Hospital, Waehringer Guertel 18-20, 1090 Vienna, Austria the problem that physicians are unfamiliar with the options of FP.

Applied FP techniques range from established to experimental surgical procedures, from suppression of the hypothalamic-ovarian axis to controlled ovarian hyperstimulation-in order to gather mature oocytes and perform an oocyte or embryo cryopreservation. Which FP technique to choose or which to combine is a crucial step in counseling patients. Particularly, the anticipated risk of impaired fertility has to be taken into account with reference to the risks, benefits and costs of the FP procedure itself, the oncologic prognosis, and most importantly the time available prior to the oncologic treatment. Controlled ovarian hyperstimulation with subsequent oocyte retrieval and cryopreservation requires up to 3 weeks, a downregulation of the ovarian function at least 5-7 days: as a consequence, we are always pressed for time because a woman's fertility in an oncologic setting can only be the second most important aspect.

This series will cover the most common fertility preservation techniques and future prospects in this scientific field [1-4]. Medical professionals and patients need to be informed about possibilities of FP techniques in order to allow the patient to make an autonomous decision concerning a future chance of parenthood.

\section{With kind regards,}

Bettina Böttcher and Julian Marschalek

Conflict of interest B. Böttcher and J. Marschalek declare that they have no competing interests. 


\section{editorial}

\section{References}

1. Böttcher, B., Goeckenjan, M. Fertility preservation procedures in girls, adolescents and women. memo. 2020;13(4). https://doi.org/10.1007/s12254-020-00620-1.

2. Reiser E, Böttcher B, Minasch D, Mangesius J, Toth B. Ovarian transposition. memo. 2020;13(4). https://doi.org/ 10.1007/s12254-020-00646-5.

3. Böttcher B, Winkler-Crepaz K. Future perspectives of fertility preservation in women. memo. 2020;13(4). https://doi. org/10.1007/s12254-020-00626-9.

4. Röthlisberger M, Nouri K. Fertility preservation in women with endometrial cancer. memo. 2020;13(4). https://doi. org/10.1007/s12254-020-00620-1.
Publisher's Note Springer Nature remains neutral with regard to jurisdictional claims in published maps and institutional affiliations.

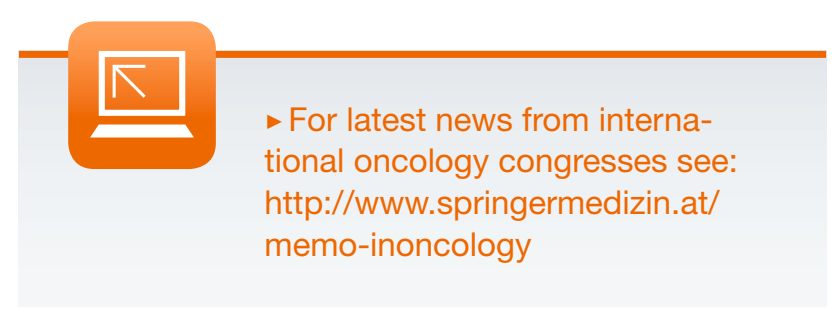

